\title{
Impact of species and antibiotic therapy of enterococcal peritonitis on 30-day mortality in critical care-an analysis of the OUTCOMEREA database
}

Anne-Cécile Morvan ${ }^{1 *}$ D, Baptiste Hengy ${ }^{1}$, Maïté Garrouste-Orgeas ${ }^{2}$, Stéphane Ruckly ${ }^{3}$, Jean-Marie Forel ${ }^{4}$, Laurent Argaud $^{5}$, Thomas Rimmelé ${ }^{1}$, Jean-Pierre Bedos ${ }^{6}$, Elie Azoulay ${ }^{7}$, Claire Dupuis $^{8}$, Bruno Mourvillier ${ }^{8}$, Carole Schwebel ${ }^{9}$, Jean-François Timsit ${ }^{8}$ and On behalf of the OUTCOMEREA study group

\begin{abstract}
Introduction: Enterococcus species are associated with an increased morbidity in intraabdominal infections (IAI). However, their impact on mortality remains uncertain. Moreover, the influence on outcome of the appropriate or inappropriate status of initial antimicrobial therapy (IAT) is subjected to debate, except in septic shock. The aim of our study was to evaluate whether an IAT that did not cover Enterococcus spp. was associated with 30-day mortality in ICU patients presenting with IAI growing with Enterococcus spp.

Material and methods: Retrospective analysis of French database OutcomeRea from 1997 to 2016. We included all patients with IAI with a peritoneal sample growing with Enterococcus. Primary endpoint was 30-day mortality.

Results: Of the 1017 patients with IAI, 76 (8\%) patients were included. Thirty-day mortality in patients with inadequate IAT against Enterococcus was higher (7/18 (39\%) vs 10/58 (17\%), $p=0.05)$; however, the incidence of postoperative complications was similar. Presence of Enterococcus spp. other than E. faecalis alone was associated with a significantly higher mortality, even greater when IAT was inadequate. Main risk factors for having an Enterococcus other than $E$. faecalis alone were as follows: SAPS score on day 0, ICU-acquired IAI, and antimicrobial therapy within 3 months prior to IAI especially with third-generation cephalosporins. Univariate analysis found a higher hazard ratio of death with an Enterococcus other than $E$. faecalis alone that had an inadequate IAT (HR $=4.4$ [1.3-15.3], $p=0.019)$ versus an adequate IAT (HR = 3.1 [1.0-10.0], $p=0.053)$. However, after adjusting for confounders (i.e., SAPS II and septic shock at IAI diagnosis, ICU-acquired peritonitis, and adequacy of IAT for other germs), the impact of the adequacy of IAT was no longer significant in multivariate analysis. Septic shock at diagnosis and ICU-acquired IAI were prognostic factors.

Conclusion: An IAT which does not cover Enterococcus is associated with an increased 30-day mortality in ICU patients presenting with an IAI growing with Enterococcus, especially when it is not an E. faecalis alone. It seems reasonable to use an IAT active against Enterococcus in severe postoperative ICU-acquired IAI, especially when a third-generation cephalosporin has been used within 3 months.
\end{abstract}

Keywords: Intensive care, Intraabdominal infections, Mortality, Enterococcus spp., Antibiotic therapy

\footnotetext{
* Correspondence: annececile.morvan@gmail.com

'Department of Anesthesiology and Critical Care Medicine, Hospices Civils de

Lyon, Edouard Herriot Teaching Hospital, 5 place d'Arsonval, 69003 Lyon,

France

Full list of author information is available at the end of the article
}

(c) The Author(s). 2019 Open Access This article is distributed under the terms of the Creative Commons Attribution 4.0 International License (http://creativecommons.org/licenses/by/4.0/), which permits unrestricted use, distribution, and

reproduction in any medium, provided you give appropriate credit to the original author(s) and the source, provide a link to the Creative Commons license, and indicate if changes were made. The Creative Commons Public Domain Dedication waiver (http://creativecommons.org/publicdomain/zero/1.0/) applies to the data made available in this article, unless otherwise stated. 


\section{Introduction}

Intra-abdominal infections (IAI) represent the second most common cause of infection in the ICU [1]. Indeed, they are complicated with septic shock in $40 \%$ of cases [2]. Despite improvements in sepsis management, mortality remains high up to $40 \%$ in nosocomial IAI $[3,4]$. The primary treatment of IAI combines early source control and adequate antimicrobial therapy.

The incidence of Enterococci in IAI is 5 to $20 \%$ in community-acquired IAI and 30 to $40 \%$ in nosocomial IAI [5]; however, the pathogenicity of Enterococci in IAI is debatable. According to Dupont, Koch, and Fisher, Enterococcus might express virulence factors and might synergize with other bacteria like Escherichia coli and anaerobes [6-8]. It has been clearly demonstrated that Enteroccoci are associated with proinflammatory responses, greater clinical disease burden, and shock [911]. So far, all authors agree with an increase in morbidity (septic shock, higher APACHE 2, and Sequential Organ Failure Assessment (SOFA) scores, higher postoperative infection scores, longer duration of mechanical ventilation and vasopressors, more relaparotomies), but the impact of Enterococcus on mortality is unclear [1216]. Some studies found that the presence of Enterococci on peritoneal samples is a predictive factor for death [17-19] whereas others did not [20, 21].

Currently, the impact on prognosis of early antimicrobial therapy against Enterococcus spp. is not known and the indication of an initial empiric anti-enterococcal therapy differs among recommendations. Thus, the aim of our study was to compare the role of appropriate versus inappropriate antimicrobial therapy on 30-day mortality in ICU patients with IAI positive for Enterococcus.

\section{Material and methods}

This study was a retrospective data analysis from the OUTCOMEREA database (OutcomeRea ${ }^{\circledR}$ ).

Data were prospectively collected daily by senior physicians with research assistants in the participating ICUs. All codes and definitions were established prior to study initiation and have been previously described [22]. We collected delay between hospitalization, diagnosis, and surgery.

Patients' age, sex, and McCabe score were recorded. Severity of illness was evaluated on the first ICU day using the Simplified Acute Physiology Score (SAPS II), Sequential Organ Failure Assessment (SOFA) score, and Glasgow Coma Scale (GCS) score. Knaus' scale definitions were used to record preexisting chronic organ failures including respiratory, cardiac, hepatic, renal, and immune system failures [23, 24]. Admission category (medical, scheduled surgery, or unscheduled surgery), admission diagnosis (cardiac, respiratory, or neurological failure, infection, and other), invasive procedures (arterial or venous central catheter, Swan-Ganz catheter, or endotracheal intubation), and treatment of organ failures (inotropic support, hemodialysis, and mechanical ventilation) and ICU-acquired infections, bacteriological samples, and daily antimicrobial therapy were also collected.

Data collected from hospitalization records were as follows: risk factors for healthcare-associated infections, antimicrobial therapy within the 3 months prior to ICU admission (particularly with cephalosporins), date of diagnosis of IAI according to clinical, biological and radiological findings, anatomical origin of IAI, localized or generalized type of IAI, community-acquired or nosocomial infection, and pathophysiological mechanisms. We also collected delay between diagnosis according to clinical, biological, and radiological findings and surgery, initial and adapted antimicrobial therapy, Enterococcus species, sensibility to antimicrobial therapy, appropriate or inappropriate type of antimicrobial therapy against Enterococcus species, day of appropriate antimicrobial therapy for Enterococcus species and other microorganisms, surgical complications, need for redo laparotomy or percutaneous drainage, and development of tertiary peritonitis.

\section{Ethical issue}

The database is in accordance with French legislation concerning biomedical research. Patients or their family gave authorization for collection, conservation, and use of their personal anonymized data. Authorizations were obtained from the CNIL (Commission Nationale de l'Informatique et des Libertés), the CCTIRS (Comité consultatif sur le traitement de l'information en matière de recherche), and the Rhône-Alpes-Auvergne Institutional Review Board.

\section{Inclusion criteria}

Adult patients over 18 years old presenting with community-acquired or nosocomial IAI with a peritoneal sample growing with Enterococcus spp. and who were admitted to the ICU between 1997 and 2016 were included.

\section{Non-inclusion criteria}

Patients presenting superinfection of necrotizing pancreatitis, missing data either on the Enterococcus species or on the antimicrobial therapy, and samples coming from drains in the postoperative period were excluded.

\section{Definition}

Enterococcus IAI was defined as an IAI which required surgery or percutaneous drainage and whose intraoperative peritoneal sample was growing with Enterococcus. Day 0 (first day of the IAI) was defined as the day of surgery.

Intra-abdominal infections were nosocomial if they appeared after more than $48 \mathrm{~h}$ of hospitalization or if there were any risk factor of healthcare-associated infection (hospitalization within 3 previous months, 
rehabilitation/long-care stay within the 30 previous days, chronic dialysis or chemotherapy within 30 days, or home-care within 30 days).

Enterococcus IAI were identified from the infectious data recorded in the database. Medical records were then accessed to confirm diagnosis and details of the surgical procedure.

Initial antimicrobial therapy (IAT) was the antimicrobial therapy started on day 0 or day 1 after surgery. Antimicrobial therapy was considered appropriate or inappropriate according to the antibiogram when available. Otherwise, it was considered appropriate if it used either a penicillin (A or ureido or carboxy) or a carbapenem for Enterococcus faecalis, E. avium, or E. durans, and vancomycin, linezolide, or tigecycline for Enterococcus faecium.

Delay between IAI (day 0) and appropriate antimicrobial therapy were extracted from the database separately for Enterococcus spp. and other germs including yeasts.

Septic shock was defined according to the Surviving Sepsis Campaign 4th edition (2016) [25]. For septic shock at diagnosis, we considered septic shock criteria within a 72-h period including the day preceding and the day following IAI diagnosis.

Pneumoniae, other bacteremia (other than from intraabdominal origin), and catheter-related bloodstream infections were considered at diagnosis of IAI if they were diagnosed within $48 \mathrm{~h}$ preceding the IAI diagnosis.

\section{Outcomes}

Primary outcome was 30-day mortality. Secondary outcomes were surgical complications, redo laparotomies or percutaneous drainage, postoperative infectious complications, and septic shock at day 30 .

\section{Statistical analysis}

Patient characteristics were expressed in numbers (percentages) and median (interquartile interval) for qualitative and quantitative variables, respectively. They were compared using chi-squared and Mann-Whitney tests respectively. The impact on day 30 mortality of Enterococcus species and inappropriate IAT on Enterococcus species were assessed with univariate Cox models. Then, multivariate Cox models adjusted on SAPS score on day 0 , acquisition of peritonitis in ICU, and adequacy of IAT on other germs were used. For every analysis, $p<0.05$ was considered significant. All statistics were done using SAS software (v 9.3, SAS Institute, Cary, NC, USA).

\section{Results}

Between 1997 and 2016, data of 1017 patients with IAI were analyzed. Only 76 IAI with Enterococcus were included (Additional file 1). Incidence of Enterococcus differed between centers (Additional file 2). Median [IQR] age was 72 [59-78]. Fifty-seven percent of patients were male. Median SAPS II score at day 0 was 52 [41-64]. Median time between admission in the hospital or in the ICU and diagnosis of IAI was 8 [5-10] and 1 [1-4] days, respectively. Eight (10.5\%) patients had a community-acquired IAI. Sixty-eight (89.5\%) patients had a nosocomial IAI, among them 2 were healthcare-associated IAI and 66 were hospital-acquired IAI. Two patients had a percutaneous drainage as an initial treatment, and 7 had a percutaneous drainage secondarily after an initial surgical treatment. IAI characteristics are described in Table 1.

Germs associated with Enterococcus were as follows: Gram-positive cocci (22\%), Gram-negative bacilli (74\%), anaerobes (20\%), and yeasts (24\%). IAI were associated with Enterococcus bacteremia in $4(5 \%)$ of cases. Eleven (14\%) of the 76 IAI were growing with only Enterococcus species. Empirical antimicrobial therapies were piperacillin-tazobactam (49\%), carbapenems (33\%), vancomycin (30\%), and third-generation cephalosporins (9\%) in combination with aminoglycosides in $70 \%$ of the cases. Initial empirical antimicrobial therapy was inappropriate against Enterococcus species isolated from peritoneal sample in 18 (23.7\%) of cases and against other germs in 12 (15.8\%) of cases. Antimicrobial therapy was modified to cover the recovered Enterococci in 13 (72\%) patients. Sensitivity to amoxicillin and vancomycin was always available. There were 3 ESBL and no VRE.

Table 2 compares patients who received adequate versus inadequate empirical therapy. The two groups were similar for year of inclusion, age, gender, causes, and origins of IAI. Thirty-day mortality was significantly higher in the group who received inadequate empiric antimicrobial therapy against Enterococcus species identified on peritoneal sample, but there was no difference in postoperative complications. In this group, Enterococcus spp. other than Enterococcus faecalis were more frequently identified. Survival curves according to adequacy of IAT against Enterococcus species identified on peritoneal sample are shown in Fig. 1.

Comparisons between patients with IAI growing with Enterococcus spp. other than Enterococcus faecalis and Enterococcus faecalis alone are described in Table 2. Day 30 mortality was significantly higher in IAI growing with $E n$ terococcus spp. other than E. faecalis alone but there was no difference in postoperative complications. Survival curves according to Enterococcus species are shown in Fig. 2.

Impact on 30-day survival of the enterococcal species and the adequacy of antibiotic therapy on enterococci is displayed on Table 3.

Univariate analysis demonstrated that the identification of species other than E. faecalis alone was associated with death and the mortality rate was greater if the antibiotic therapy was inadequate against Enterococcus spp. identified on peritoneal samples. 
Table 1 Population characteristics. Results expressed in numbers (percentages) except *median and interquartile interval [1st-3rd]. IAl intraabdominal infection

\begin{tabular}{|c|c|}
\hline Variables & $\begin{array}{l}\text { All IAI with } \\
\text { Enterococcus } \\
\text { spp. }(n=76)\end{array}$ \\
\hline Age (years)* & $71.7[59.0-78.1]$ \\
\hline Gender (M/F) & $43 / 33$ \\
\hline Day 0 SAPS score* & $48[37-57]$ \\
\hline Immunocompromised status & $20(26.3 \%)$ \\
\hline Hospital admission-IAl time* & $8[2-18]$ \\
\hline ICU admission-IAI time* & $1[1-4]$ \\
\hline IAI diagnosis-surgery time & $0[0-0]$ \\
\hline E. faecium & $28(36.8 \%)$ \\
\hline E. faecalis & $46(60.5 \%)$ \\
\hline Other Enterococcus spp. & $9(11.8 \%)$ \\
\hline ICU acquired & $24(31.6 \%)$ \\
\hline Nosocomial & $68(89.5 \%)$ \\
\hline Postoperative & $53(69.7 \%)$ \\
\hline Enterococcal bacteremia & $4(5.3 \%)$ \\
\hline Septic shock at time of IAI diagnosis & $53(69.7 \%)$ \\
\hline \multicolumn{2}{|l|}{ Source control } \\
\hline Surgery & $74(97.4 \%)$ \\
\hline Percutaneous drainage & $2(2.6 \%)$ \\
\hline \multicolumn{2}{|l|}{ IAI anatomical origin } \\
\hline Colon & $32(42.7 \%)$ \\
\hline Small intestine & $19(25.3 \%)$ \\
\hline Hepatobiliary & $12(16 \%)$ \\
\hline Gastroduodenal & $8(10.7 \%)$ \\
\hline \multicolumn{2}{|l|}{ Pathophysiology of IAI } \\
\hline Perforation & $22(28.9 \%)$ \\
\hline Intraabdominal abscess & $27(35.5 \%)$ \\
\hline Fistula & $26(34.2 \%)$ \\
\hline Necrosis & 19 (25.0\%) \\
\hline Surgical complications & $35(46.1 \%)$ \\
\hline Intraabdominal abscess & $20(26.3 \%)$ \\
\hline Wound infection & 19 (25.0\%) \\
\hline Fistula & $8(10.5 \%)$ \\
\hline Suture line disruption & $2(2.6 \%)$ \\
\hline Evisceration & $1(1.3 \%)$ \\
\hline Relaparotomy or percutaneous drainage at day 30 & $23(30.3 \%)$ \\
\hline $\begin{array}{l}\text { IAI-relaparotomy or IAI-percutaneous drainage time } \\
\text { (days)* }\end{array}$ & $10[6-20]$ \\
\hline Tertiary peritonitis & $16(21.3 \%)$ \\
\hline Postoperative infectious complications at day 30 & $24(31.6 \%)$ \\
\hline Septic shock at day 30 & $44(57.9 \%)$ \\
\hline Mortality at day 30 & $17(22.4 \%)$ \\
\hline
\end{tabular}

However, after adjusting for confounders (i.e., SAPS II and septic shock at IAI diagnosis, ICU-acquired peritonitis, and adequacy of antibiotic therapy for other germs), the impact of the adequacy of antimicrobial therapy was no longer significant (Table 3). The impact of culturing enterococci other than $E$. faecalis remained a poor prognosis $(\mathrm{HR}=2.283$ [0.730-7.141], $p=0.156)$. A septic shock at IAI diagnosis and an ICU-acquired IAI were associated with death regardless of the adequacy of IAT and Enterococcus species.

Survival curves according to adequacy of IAT on germs other than Enterococcus species identified on peritoneal sample are shown in Additional file 3.

Neither adequacy of IAT nor Enterococcus species were associated with redo laparotomy on day 30 or percutaneous drainage in both univariate and multivariate analyses.

\section{Discussion}

In a large cohort of severe peritonitis with enterococci admitted in the ICU, we found that inadequate IAT against Enterococcus spp. was associated with increased 30-day mortality. We also found that Enterococcus spp. other than $E$. faecalis alone were more frequent in cases of previous therapy with third-generation cephalosporins in the past 3 months and in ICU-acquired peritonitis. It was associated with inadequate IAT and a poorer prognosis.

Intraabdominal infections growing with Enterococcus are associated with a worse prognosis. Theunissen et al. showed that presence of Enterococci is a predictive factor for death in both nosocomial and community-acquired IAI and is independently associated with mortality (OR $3.88(1.05-14.28) p=0.044)$ [19]. In our study, the large majority of IAI was nosocomial $(90 \%)$ and mortality was high (22\% in the whole population and $39 \%$ in the inappropriate first antimicrobial therapy group). It was comparable with previously published data: 39\% in Montravers et al. study (mainly postoperative IAI with multidrug-resistant bacteria), $25 \%$ in Sotto et al. (ICU IAI), and $25 \%$ in Theunissen et al. (40\% of nosocomial IAI) $[17,19,26]$. Recently, Freedberg et al. found in a cohort of 301 medical ICU patients that VRE colonization and Enterococcus domination were both associated with death or all-cause infection at 30 days (aHR 1.46, 95\% CI $1.06-2.00$ and aHR $1.47,95 \%$ CI $1.00-2.19$, respectively) after adjusting for severity of illness [27].

We found that an inappropriate IAT against Enterococcus spp. identified on peritoneal samples was associated with a higher 30-day mortality. The only prospective randomized trial that compared treatment with antimicrobial therapy active or inactive against Enterococcus (penicillin vs cephalosporin) concluded no differences between both groups [28]. This study included only non-severe community-acquired IAI (median APACHE scores 10 and 9); the number of IAI growing with Enterococcus was very low (6 
Table 2 Comparison between patients who received an appropriate initial antimicrobial therapy against Enterococcus species isolated from peritoneal sample versus patients who did not and between the groups E. faecalis alone and Enterococcus other than E. faecalis alone. Results expressed in numbers (percentages) apart from *median and interquartile interval [1st-3rd]. ${ }^{*}$ Diagnosed within $48 \mathrm{~h}$ preceding IAl diagnosis. IAl intraabdominal infections

\begin{tabular}{|c|c|c|c|c|c|c|}
\hline Variables & $\begin{array}{l}\text { Initial antimicrobial } \\
\text { therapy inactive against } \\
\text { Enterococcus }(n=18)\end{array}$ & $\begin{array}{l}\text { Initial antimicrobial } \\
\text { therapy active against } \\
\text { Enterococcus }(n=58)\end{array}$ & $p$ & $\begin{array}{l}\text { Enterococcus other } \\
\text { than } E \text {. faecalis } \\
\text { alone }(n=34)\end{array}$ & $\begin{array}{l}\text { E. faecalis alone } \\
\text { without other } \\
\text { Enterococcus species } \\
(n=42)\end{array}$ & $p$ \\
\hline $\begin{array}{l}\text { Antimicrobial therapy use }<3 \text { months prior } \\
\text { to IAI }\end{array}$ & $9(50.0)$ & $34(58.6)$ & 0.519 & $26(76.5)$ & $17(40.5)$ & 0.002 \\
\hline $\begin{array}{l}\text { Third-generation cephalosporin use } \\
<3 \text { months prior to IAI }\end{array}$ & $6(33.3)$ & $7(12.1)$ & 0.036 & $9(26.5)$ & $4(9.5)$ & 0.051 \\
\hline Hospital admission-IAl time* & $4[2-7]$ & 10 [3-22] & 0.016 & $10[3-24]$ & $6[2-13]$ & 0.104 \\
\hline ICU admission-IAI time* & $1[1-4]$ & $1[1-5]$ & 0.622 & $2[1-7]$ & $1[1-1]$ & 0.024 \\
\hline IAI diagnosis-surgery time* & $0[0-0]$ & $0[0-0]$ & 0.728 & $0[0-0]$ & $0[0-0]$ & 0.986 \\
\hline Postoperative IAI & $7(38.9)$ & $18(79.3)$ & 0.001 & $23(67.6)$ & $30(71.4)$ & 0.721 \\
\hline ICU-acquired IAI & $8(44.4)$ & $16(27.6)$ & 0.179 & $15(44.1)$ & $9(21.4)$ & 0.034 \\
\hline SAPS on day $0^{*}$ & $56.5[39-63]$ & $45.5[37-55]$ & 0.029 & $50.0[39-60]$ & $45.5[36-54]$ & 0.051 \\
\hline Day 0 vasopressor use & $14(77.8)$ & $40(69.0)$ & 0.471 & $27(79.4)$ & $27(64.3)$ & 0.148 \\
\hline Septic shock at diagnosis & $15(83.3)$ & $38(65.5)$ & 0.151 & $26(76.5)$ & $27(64.3)$ & 0.250 \\
\hline Pneumonia** & $1(5.6)$ & $1(1.7)$ & 0.375 & $1(2.9)$ & $1(2.4)$ & 0.879 \\
\hline Other bacteremia** & $2(11.1)$ & $4(6.9)$ & 0.562 & $2(5.9)$ & $4(9.5)$ & 0.558 \\
\hline Catheter-related bloodstream infection** & $0(0)$ & $3(5.2)$ & 0.151 & $1(2.9)$ & $2(4.8)$ & 0.685 \\
\hline $\begin{array}{l}\text { Adequate initial antimicrobial therapy } \\
\text { against other germs }\end{array}$ & $14(77.8)$ & $50(86.2)$ & 0.392 & $28(82.4)$ & $36(85.7)$ & 0.689 \\
\hline $\begin{array}{l}\text { Inadequate initial antimicrobial therapy } \\
\text { against identified Enterococcus }\end{array}$ & $18(100)$ & $0(0)$ & $\begin{array}{l}< \\
0.001\end{array}$ & $22(64.7)$ & $36(85.7)$ & 0.032 \\
\hline $\begin{array}{l}\text { Vancomycin in initial antimicrobial } \\
\text { regimen }\end{array}$ & $1(5.6)$ & $22(37.9)$ & 0.009 & & & \\
\hline E. faecium isolated in peritoneal sample & $11(61.1)$ & $17(29.3)$ & 0.015 & & & \\
\hline E. faecalis isolated in peritoneal sample & $8(44.4)$ & $38(65.5)$ & 0.110 & & & \\
\hline $\begin{array}{l}\text { Other Enterococcus isolated in peritoneal } \\
\text { sample }\end{array}$ & $2(11.1)$ & $7(12.1)$ & 0.913 & & & \\
\hline Day 30 surgical complications & $8(44.4)$ & $27(46.6)$ & 0.875 & $15(44.1)$ & $20(47.6)$ & 0.761 \\
\hline $\begin{array}{l}\text { Day } 30 \text { relaparotomy or percutaneous } \\
\text { drainage }\end{array}$ & $4(22.2)$ & 19 (32.8) & 0.395 & $7(20.6)$ & $16(38.1)$ & 0.099 \\
\hline Day 30 infectious complications & $7(38.9)$ & $17(29.3)$ & 0.445 & $12(35.3)$ & $12(28.6)$ & 0.531 \\
\hline Day 30 mortality & $7(38.9)$ & $10(17.2)$ & 0.054 & $12(35.3)$ & $5(11.9)$ & 0.015 \\
\hline
\end{tabular}

over 110 peritonitis) [28]. However, in a population of 200 postoperative IAI among which 42 were growing with $E n-$ terococcus, Sitges-Serra et al. found that mortality was higher when IAT did not cover these Enterococcus (21\% vs $4 \%, p<0.001$ ) [14]. In Enterococcus bacteremia, early use of anti-Enterococcus antimicrobial therapy within $48 \mathrm{~h}$ is a protective factor against death [29].

Several studies have evaluated the impact on mortality of the adequacy of an initial empiric antimicrobial therapy for all peritoneal germs in general (not only for Enterococcus). Sotto, Mosdell, Montravers, and Sturkenboom did not find any difference $[17,20,30,31]$. However, Sotto studied ICU IAI but the numbers were small in the inappropriate antimicrobial therapy group (14 patients) and the three other studies included mainly patients with community-acquired and non-severe IAI. Nevertheless, Montravers' study on postoperative IAI growing with multiresistant bacteria (2009) and Harbarth's study on severe sepsis and septic shock showed that an inappropriate IAT was an independent risk factor of death in IAI [26, 32]. Thus, it seems that an appropriate IAT has an impact on mortality especially in severe postoperative IAI with septic shock.

However, we did not find more redo laparotomies or percutaneous drainages or infectious complications at day 30 when IAT was inappropriate. Other studies showed that an inappropriate IAT against all microbials 


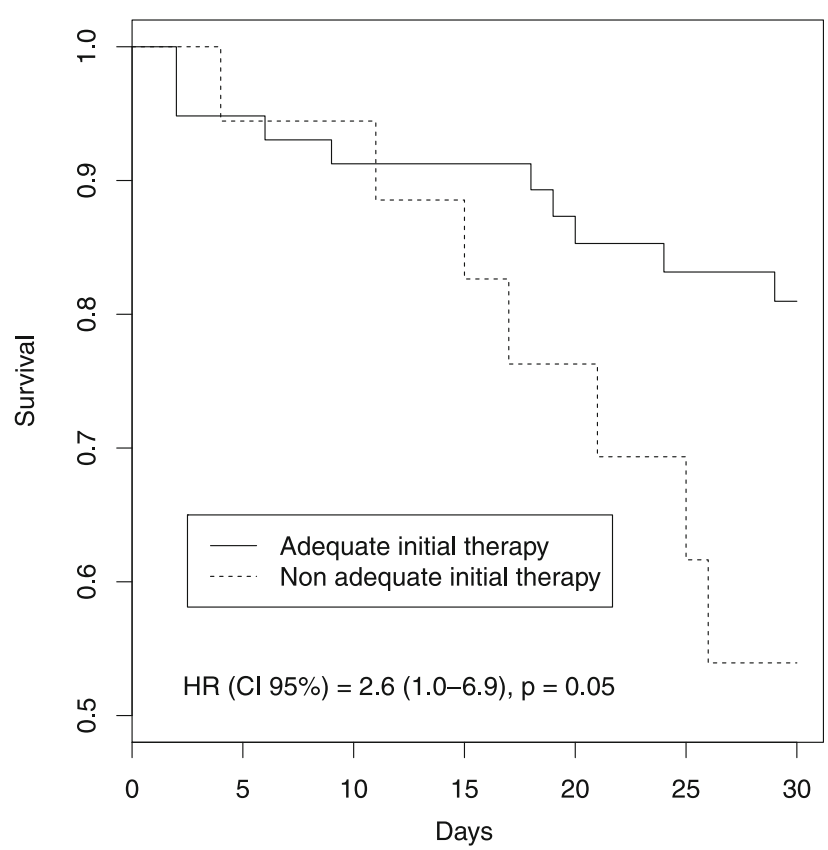

No. of patients at risk

$\begin{array}{lccccccc}\text { Adequate } & 58 & 53 & 51 & 50 & 43 & 39 & 37 \\ \text { Non adequate } & 18 & 16 & 16 & 15 & 11 & 9 & 7\end{array}$

Fig. 1 Survival according to adequacy of initial antimicrobial therapy on Enterococcus species identified on peritoneal sample (Kaplan-Meier plot)

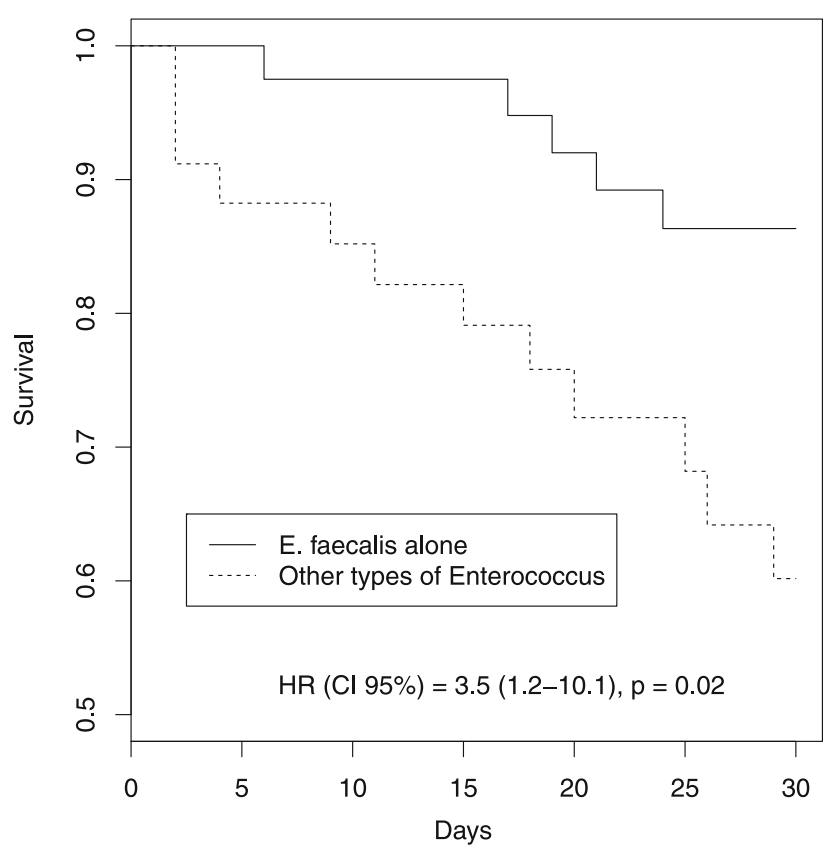

No. of patients at risk

$\begin{array}{llllllll}\text { E. faecalis } & 42 & 40 & 39 & 38 & 33 & 30 & 29 \\ \text { Other } & 34 & 29 & 28 & 27 & 21 & 18 & 15\end{array}$

Fig. 2 Survival according to Enterococcus species (Kaplan-Meier plot) 
Table 3 Univariate and multivariate models evaluating the impact of Enterococci spp. and adequacy of initial antimicrobial therapy on enterococci on day 30 mortality, with adjustment on SAPS score and septic shock at diagnosis, acquisition of IAI in ICU, and adequacy of initial antimicrobial therapy on other germs. *As interaction term between adequate therapy and other than $E$. faecalis alone IAI was significant, we created a variable with three classes, E. faecalis IAI was the reference

\begin{tabular}{|c|c|c|c|c|}
\hline Parameters & $\mathrm{HR}$ & Cl 95\% & & $p$ value \\
\hline \multicolumn{5}{|l|}{ Univariate models } \\
\hline No E. faecalis alone & 3.545 & 1.247 & 10.079 & 0.018 \\
\hline Inappropriate IAT on Enterococcus spp. & 2.612 & 0.991 & 6.883 & 0.052 \\
\hline No E. faecalis alone + inadequate IAT on Enterococcus spp.* & 4.427 & 1.277 & 15.344 & 0.019 \\
\hline No E. faecalis alone + adequate IAT on Enterococcus spp.* & 3.106 & 0.985 & 9.796 & 0.053 \\
\hline \multicolumn{5}{|l|}{ Multivariate models } \\
\hline Inappropriate IAT on Enterococcus spp. & 1.445 & 0.498 & 4.195 & 0.498 \\
\hline SAPS on day 0 & 1.003 & 0.964 & 1.043 & 0.893 \\
\hline ICU-acquired peritonitis & 3.282 & 1.191 & 9.041 & 0.021 \\
\hline Adequate IAT on other germs & 1.364 & 0.299 & 6.221 & 0.689 \\
\hline Septic shock at diagnosis & 11.828 & 1.451 & 96.396 & 0.021 \\
\hline No E. faecalis alone & 2.283 & 0.730 & 7.141 & 0.156 \\
\hline SAPS on day 0 & 1.003 & 0.964 & 1.043 & 0.890 \\
\hline ICU-acquired peritonitis & 2.613 & 0.898 & 7.605 & 0.078 \\
\hline Adequate IAT on other germs & 1.469 & 0.312 & 6.927 & 0.627 \\
\hline Septic shock at diagnosis & 11.101 & 1.386 & 88.887 & 0.023 \\
\hline No E. faecalis alone + inadequate IAT on Enterococcus spp. & 2.290 & 0.551 & 9.519 & 0.254 \\
\hline No E. faecalis alone + adequate IAT on Enterococcus spp. & 2.281 & 0.690 & 7.535 & 0.176 \\
\hline SAPS on day 0 & 1.003 & 0.964 & 1.043 & 0.890 \\
\hline ICU-acquired peritonitis & 2.611 & 0.859 & 7.937 & 0.091 \\
\hline Adequate IAT on other germs & 1.470 & 0.307 & 7.031 & 0.629 \\
\hline Septic shock at diagnosis & 11.094 & 1.371 & 89.776 & 0.024 \\
\hline
\end{tabular}

found on the peritoneal sample was associated with a higher morbidity both in community-acquired and nosocomial IAI in terms of length of stay, wound infection, redo laparotomies, and postoperative complications [14, 26, 30, 31, 33, 34].

An inadequate IAT against Enterococcus spp. identified on peritoneal samples was associated with postoperative IAI, time between hospital admission and IAI, antimicrobial therapy with third-generation cephalosporins within the 3 months prior to IAI, IAI with E. faecium or any Enterococcus species other than E. faecalis, and an IAT that did not include vancomycin. This implies that adequacy of IAT was associated with the use of vancomycin. WSES recommendations are to cover Enterococcus in postoperative IAI but not in community-acquired IAI [35]. For IDSA, "empiric anti-enterococcal therapy is recommended for patients with healthcare-associated IAI, particularly those with postoperative infection, those who have previously received cephalosporins or other antimicrobial agents selecting for Enterococcus species, immunocompromised patients, and those with valvular heart disease or prosthetic intravascular materials". "Anti-enterococcal therapy should be directed against Enterococcus faecalis", and "antibiotics that can potentially be used ... include ampicillin, piperacillin-tazobactam or vancomycin" [36].

In multivariate analysis, adequacy of IAT on Enterococcus species was no longer independently associated with survival after adjustment on adequacy of IAT on other germs, time of onset of IAI (ICU-acquired IAI), SAPS score, and septic shock at time of diagnosis. However, septic shock at diagnosis and ICU-acquired IAI were risk factors for death regardless of the Enterococcus species and adequacy of IAT. It has been shown multiple times in the literature that an IAI with septic shock has a higher mortality rate than an IAI without septic shock $[2,20,37]$ and our study confirms this finding.

Finally, we found a difference in 30-day mortality depending on Enterococcus species: E. faecalis alone vs Enterococcus other than E. faecalis alone (mostly E. faecium). In univariate analysis, we found a higher hazard ratio for death with an Enterococcus other than E. faecalis alone that had been initially inadequately treated compared to adequately treated; this suggests that the species of Enterococcus had a greater impact than adequacy of IAT on 
survival. Risk factors of having an Enterococcus other than $E$. faecalis alone in univariate analysis were SAPS score on day 0, Cardio SOFA score on ICU admission, time between ICU admission and IAI, ICU-acquired IAI, antimicrobial therapy within the 3 months prior to IAI especially with third-generation cephalosporins, antimicrobial therapy prior to relaparotomy in postoperative IAI, and an inadequate IAT. Previous studies on enterococcal bacteremia found that SAPS score, prior antimicrobial therapy exposure (mainly penicillin and thirdgeneration cephalosporins, but also carbapenems, aminoglycosides, and clindamycin), hematologic malignancies and neutropenia, current corticosteroid therapy, organ dysfunction, gastrointestinal disease (vs genitourinary disease), and nosocomial acquisition were risk factors for E. faecium isolation (vs E. faecalis) [38-42]. Some studies found a higher mortality with $E$. faecium than with $E$. faecalis bloodstream infections [38, 40, 42]. Our findings are consistent with those studies. Enterococcus spp., especially other than E. faecalis, are associated with a poorer prognosis in IAI and their presence is often associated with a previous antimicrobial therapy within the 3 months prior to IAI and especially with third-generation cephalosporins.

\section{Our study has several limits}

First, the number of patients especially in the inappropriate IAT group was low. We can explain the small number of patients by the very selected population we studied. But to our knowledge, this is the second largest cohort of IAI growing with Enterococcus after Kaffarnik et al.'s cohort [21]. However, because the population is highly selected, the results of our study should only be taken as an exploratory approach and further studies are needed to confirm those results.

Second, this is a retrospective study although data was extracted from a multicentric national database in which data are collected prospectively. Presence of missing data led us to read medical records, but since almost one third of medical records were not available, we had to exclude nearly a hundred of patients. Information bias cannot be excluded especially about previous antimicrobial therapy before hospital admission.

Third, we had no prospectively collected data about the quality of source control. All patients had either surgery or percutaneous drainage. Yet it is known that a good quality of source control is associated with a reduction in mortality in IAI [43]. Therefore, it is a limitation to conclude on mortality without information about source control quality. However, evaluation would have been subjective since there is no validated questionnaire to evaluate source control quality apart from the checklist recommended by Solomkin et al. to be done at the end of surgery or percutaneous drainage [44].
Finally, data collection was extended over 20 years. Both surgery and critical care evolved during this period. Critical care management improved widely for the last 10 years which led to a better prognosis in sepsis. However, there were no difference in years of inclusion between groups.

\section{Conclusion}

We found that inadequacy of IAT on Enterococcus species identified on peritoneal sample was associated with a worse 30-day survival especially when it was not an $E$. faecalis alone. This inadequacy was partly due to the absence of vancomycin in the empiric antibiotic regimen. These results should encourage the physician to use an antimicrobial regimen active against non-faecalis Enterococcus (like vancomycin) in severe, postoperative, ICUacquired IAI, especially when an antimicrobial therapy with third-generation cephalosporins has been used within 3 months preceding IAI. Our study also suggests that IAI with non E. faecalis Enterococci have a poorer prognosis than IAI with $E$. faecalis alone. It would be interesting to conduct a prospective and larger study to confirm these results.

\section{Additional files}

Additional file 1: Flowchart. $|\mathrm{A}|=$ intraabdominal infection. (DOCX $46 \mathrm{~kb}$ )

Additional file 2: Incidence of Enterococcus in each center. $|A|=$ intraabdominal infection. (DOCX $13 \mathrm{~kb})$

Additional file 3: Survival rate according to adequacy of initial antimicrobial therapy on germs other than Enterococcus species identified on peritoneal sample (Kaplan-Meier plot, $n=64)$. (PDF $25 \mathrm{~kb}$ )

\section{Abbreviations}

IAl: Intraabdominal infection; IAT: Initial antimicrobial therapy; GCS: Glasgow Coma Scale; SAPS II: Simplified Acute Physiology Score II; SOFA: Sequential Organ Failure Assessment

\section{Acknowledgements}

A special thank you to Dr. Eric You-Ten, University of Toronto, Department of Anesthesia, for his final reading and corrections of English terms.

\section{Authors' contributions}

ACM, BH, GM, and JFT designed the study. ACM and SR collected the data from the database. JFT and SR gathered the medical records from MGO, JMF, and CS. ACM collected the data from the medical records. SR was the major contributor in analyzing the data and creating the graphs. ACM was the major contributor in writing the article. $\mathrm{BH}, \mathrm{GM}, \mathrm{JFT}$, and $\mathrm{CD}$ were major contributors in improving the article. All authors read and approved the final manuscript.

\section{Funding}

None

Availability of data and materials

The datasets generated and/or analyzed during the current study are available in the OutcomeRea database.

Ethics approval and consent to participate

The database is in accordance with the French legislation concerning biomedical research. Patients or their family gave authorization for collection, conservation, and use of their personal anonymized data. Authorizations were obtained from 
the CNIL (Commission Nationale de I'Informatique et des Libertés), the CCTIRS (Comité consultatif sur le traitement de l'information en matière de recherche), and the Rhône-Alpes-Auvergne Institutional Review Board.

\section{Consent for publication}

Not applicable.

\section{Competing interests}

The authors declare that they have no competing interests.

\section{Author details}

'Department of Anesthesiology and Critical Care Medicine, Hospices Civils de Lyon, Edouard Herriot Teaching Hospital, 5 place d'Arsonval, 69003 Lyon, France. ${ }^{2}$ Polyvalent ICU, St Joseph Hospital, Paris, France. ${ }^{3}$ UMR 1137 - IAME Team 5 - DeSCID: Decision Sciences in Infectious Diseases, Control and Care INSERM Paris Diderot University, Sorbonne Paris Cité, Paris, France. ${ }^{4}$ Medical ICU, Respiratory Distress and Severe Infections, Nord Hospital, URMITE CNRS-UMR 6236, Aix-Marseille University, AP-HM, Marseille, France. ${ }^{5}$ Medical ICU, Hospices Civils de Lyon, Edouard Herriot Teaching Hospital, Lyon, France. ${ }^{6}$ Intensive Care Department, GHT Sud Yvelines, Centre Hospitalier de Versailles - Site André Mignot, Le Chesnay, Cedex, France. ${ }^{7}$ Medical ICU, APHP, Saint-Louis Hospital, ECSTRA Team, and Clinical Epidemiology, UMR 1153 (Center of Epidemiology and Biostatistics, Sorbonne Paris Cité, CRESS), INSERM, Paris Diderot Sorbonne University, Paris, France. ${ }^{8}$ Medical and Infectious Diseases ICU, Bichat University Hospital, AP-HP, Paris, France. ${ }^{9}$ Medical ICU, Albert Michallon Hospital, Grenoble 1 University, Grenoble, France.

\section{Received: 8 June 2019 Accepted: 22 August 2019} Published online: 06 September 2019

\section{References}

1. Vincent J-L, Sakr Y, Sprung CL, Ranieri VM, Reinhart K, Gerlach H, et al. Sepsis in European intensive care units: results of the SOAP study. Crit Care Med. 2006;34(2):344-53.

2. Riché FC, Dray X, Laisné M-J, Matéo J, Raskine L, Sanson-Le Pors M-J, et al. Factors associated with septic shock and mortality in generalized peritonitis: comparison between community-acquired and postoperative peritonitis. Crit Care Lond Engl. 2009;13(3):R99.

3. Montravers P, Dupont H, Gauzit R, Veber B, Auboyer C, Blin P, et al. Candida as a risk factor for mortality in peritonitis. Crit Care Med. 2006;34(3):646-52.

4. Roehrborn A, Thomas L, Potreck O, Ebener C, Ohmann C, Goretzki PE, et al. The microbiology of postoperative peritonitis. Clin Infect Dis. 2001;33(9): 1513-9.

5. Montravers P, Dupont H, Leone M, Constantin J-M, Mertes P-M. Société française d'anesthésie et de réanimation (Sfar), et al. Guidelines for management of intra-abdominal infections. Anaesth Crit Care Pain Med. 2015;34(2):117-30.

6. Dupont $\mathrm{H}$, Montravers $\mathrm{P}$, Mohler J, Carbon C. Disparate findings on the role of virulence factors of Enterococcus faecalis in mouse and rat models of peritonitis. Infect Immun. 1998;66(6):2570-5.

7. Koch S, Hufnagel M, Theilacker C, Huebner J. Enterococcal infections: host response, therapeutic, and prophylactic possibilities. Vaccine. 2004;22(7):822-30.

8. Fisher K, Phillips C. The ecology, epidemiology and virulence of Enterococcus. Microbiol Read Engl. 2009;155(Pt 6):1749-57.

9. Matlow AG, Bohnen JM, Nohr C, Christou N, Meakins J. Pathogenicity of enterococci in a rat model of fecal peritonitis. J Infect Dis. 1989;160(1):142-5.

10. Montravers $P$, Andremont A, Massias L, Carbon C. Investigation of the potential role of Enterococcus faecalis in the pathophysiology of experimental peritonitis. J Infect Dis. 1994;169(4):821-30.

11. Montravers P, Mohler J, Saint Julien L, Carbon C. Evidence of the proinflammatory role of Enterococcus faecalis in polymicrobial peritonitis in rats. Infect Immun. 1997;65(1):144-9.

12. Burnett RJ, Haverstock DC, Dellinger EP, Reinhart HH, Bohnen JM, Rotstein $O D$, et al. Definition of the role of enterococcus in intraabdominal infection: analysis of a prospective randomized trial. Surgery. 1995;118(4):716-21 discussion 721-723.

13. Wacha H, Hau T, Dittmer R, Ohmann C. Risk factors associated with intraabdominal infections: a prospective multicenter study. Peritonitis Study Group Langenbecks Arch Surg. 1999;384(1):24-32.
14. Sitges-Serra A, López MJ, Girvent M, Almirall S, Sancho JJ. Postoperative enterococcal infection after treatment of complicated intra-abdominal sepsis. Br J Surg. 2002;89(3):361-7.

15. Gauzit R, Péan Y, Barth X, Mistretta F, Lalaude O, Top Study Team. Epidemiology, management, and prognosis of secondary non-postoperative peritonitis: a French prospective observational multicenter study. Surg Infect. 2009;10(2):119-27.

16. Cercenado E, Torroba L, Cantón R, Martínez-Martínez L, Chaves F, GarcíaRodríguez JA, et al. Multicenter study evaluating the role of enterococci in secondary bacterial peritonitis. J Clin Microbiol. 2010;48(2):456-9.

17. Sotto A, Lefrant JY, Fabbro-Peray P, Muller L, Tafuri J, Navarro F, et al. Evaluation of antimicrobial therapy management of 120 consecutive patients with secondary peritonitis. J Antimicrob Chemother. 2002;50(4):569-76.

18. Dupont H, Friggeri A, Touzeau J, Airapetian N, Tinturier F, Lobjoie E, et al. Enterococci increase the morbidity and mortality associated with severe intra-abdominal infections in elderly patients hospitalized in the intensive care unit. J Antimicrob Chemother. 2011;66(10):2379-85.

19. Theunissen C, Cherifi S, Karmali R. Management and outcome of high-risk peritonitis: a retrospective survey 2005-2009. Int J Infect Dis. 2011;15(11):e769-73.

20. Montravers P, Lepape A, Dubreuil L, Gauzit R, Pean Y, Benchimol D, et al. Clinical and microbiological profiles of community-acquired and nosocomial intra-abdominal infections: results of the French prospective, observational EBIIA study. J Antimicrob Chemother. 2009;63(4):785-94.

21. Kaffarnik MF, Urban M, Hopt UT, Utzolino S. Impact of enterococcus on immunocompetent and immunosuppressed patients with perforation of the small or large bowel. Technol Health Care. 2012;20(1):37-48.

22. Lautrette A, Garrouste-Orgeas M, Bertrand P-M, Goldgran-Toledano D, Jamali S, Laurent $\mathrm{V}$, et al. Respective impact of no escalation of treatment, withholding and withdrawal of life-sustaining treatment on ICU patients' prognosis: a multicenter study of the Outcomerea research group. Intensive Care Med. 2015;41(10):1763-72.

23. Le Gall JR, Lemeshow S, Saulnier F. A new simplified acute physiology score (SAPS II) based on a European/North American multicenter study. JAMA 1993;270(24):2957-63.

24. Knaus WA, Draper EA, Wagner DP, Zimmerman JE. Prognosis in acute organ-system failure. Ann Surg. 1985;202(6):685-93.

25. Rhodes A, Evans LE, Alhazzani W, Levy MM, Antonelli M, Ferrer R, et al. Surviving Sepsis Campaign: International Guidelines for Management of Sepsis and Septic Shock: 2016. Intensive Care Med. 2017;43(3):304-77.

26. Montravers P, Gauzit R, Muller C, Marmuse JP, Fichelle A, Desmonts JM. Emergence of antibiotic-resistant bacteria in cases of peritonitis after intraabdominal surgery affects the efficacy of empirical antimicrobial therapy. Clin Infect Dis. 1996;23(3):486-94.

27. Freedberg DE, Zhou MJ, Cohen ME, Annavajhala MK, Khan S, Moscoso DI, et al. Pathogen colonization of the gastrointestinal microbiome at intensive care unit admission and risk for subsequent death or infection. Intensive Care Med. 2018:44(8):1203-11.

28. Röhrborn A, Wacha H, Schöffel U, Billing A, Aeberhard P, Gebhard B, et al. Coverage of enterococci in community acquired secondary peritonitis: results of a randomized trial. Surg Infect. 2000;1(2):95-107.

29. Vergis EN, Hayden MK, Chow JW, Snydman DR, Zervos MJ, Linden PK, et al. Determinants of vancomycin resistance and mortality rates in enterococcal bacteremia. A prospective multicenter study. Ann Intern Med. 2001;135(7): 484-92.

30. Mosdell DM, Morris DM, Voltura A, Pitcher DE, Twiest MW, Milne RL, et al . Antibiotic treatment for surgical peritonitis. Ann Surg. 1991;214(5):543-9.

31. Sturkenboom MCJM, Goettsch WG, Picelli G. in 't Veld B, Yin DD, de Jong $\mathrm{RB}$, et al. Inappropriate initial treatment of secondary intra-abdominal infections leads to increased risk of clinical failure and costs. Br J Clin Pharmacol. 2005;60(4):438-43.

32. Harbarth S, Garbino J, Pugin J, Romand JA, Lew D, Pittet D. Inappropriate initial antimicrobial therapy and its effect on survival in a clinical trial of immunomodulating therapy for severe sepsis. Am J Med. 2003;115(7):529-35.

33. Cattan P, Yin DD, Sarfati E, Lyu R, De Zelicourt M, Fagnani F. Cost of care for inpatients with community-acquired intra-abdominal infections. Eur J Clin Microbiol Infect Dis Off Publ Eur Soc Clin Microbiol. 2002;21(11):787-93.

34. Krobot K, Yin D, Zhang Q, Sen S, Altendorf-Hofmann A, Scheele J, et al. Effect of inappropriate initial empiric antibiotic therapy on outcome of patients with community-acquired intra-abdominal infections requiring surgery. Eur J Clin Microbiol Infect Dis Off Publ Eur Soc Clin Microbiol. 2004; 23(9):682-7. 
35. Sartelli M, Catena F, Abu-Zidan FM, Ansaloni L, Biffl WL, Boermeester MA, et al. Management of intra-abdominal infections: recommendations by the WSES 2016 consensus conference. World J Emerg Surg WJES. 2017;12:22.

36. Solomkin JS. Evaluating evidence and grading recommendations: the SIS/ IDSA guidelines for the treatment of complicated intra-abdominal infections. Surg Infect. 2010;11(3):269-74.

37. Kang C-I, Chung DR, Ko KS, Peck KR, Song J-H. Korean Network for the Study of Infectious Diseases (KONSID). Risk factors for mortality and impact of broad-spectrum cephalosporin resistance on outcome in bacteraemic intra-abdominal infections caused by Gram-negative bacilli. Scand J Infect Dis. 2011:43(3):202-8.

38. Noskin GA, Peterson LR, Warren JR. Enterococcus faecium and Enterococcus faecalis bacteremia: acquisition and outcome. Clin Infect Dis. 1995;20(2): 296-301.

39. Suppola JP, Kuikka A, Vaara M, Valtonen W. Comparison of risk factors and outcome in patients with Enterococcus faecalis vs Enterococcus faecium bacteraemia. Scand J Infect Dis. 1998;30(2):153-7.

40. Conde-Estévez D, Grau S, Albanell J, Terradas R, Salvadó M, Knobel H. Clinical characteristics and outcomes of patients with vancomycinsusceptible Enterococcus faecalis and Enterococcus faecium bacteraemia in cancer patients. Eur J Clin Microbiol Infect Dis. 2011;30(1):103-8.

41. Gudiol C, Ayats J, Camoez M, Domínguez MÁ, García-Vidal C, Bodro M, et al. Increase in bloodstream infection due to vancomycin-susceptible Enterococcus faecium in cancer patients: risk factors, molecular epidemiology and outcomes. PLoS One. 2013;8(9):e74734.

42. Billington EO, Phang SH, Gregson DB, Pitout JDD, Ross T, Church DL, et al. Incidence, risk factors, and outcomes for Enterococcus spp. blood stream infections: a population-based study. Int J Infect Dis. 2014;26:76-82.

43. Mulier S, Penninckx F, Verwaest C, Filez L, Aerts R, Fieuws S, et al. Factors affecting mortality in generalized postoperative peritonitis: multivariate analysis in 96 patients. World J Surg. 2003;27(4):379-84.

44. Solomkin JS, Ristagno RL, Das AF, Cone JB, Wilson SE, Rotstein OD, et al. Source control review in clinical trials of anti-infective agents in complicated intra-abdominal infections. Clin Infect Dis. 2013;56(12):1765-73.

\section{Publisher's Note}

Springer Nature remains neutral with regard to jurisdictional claims in published maps and institutional affiliations.

Ready to submit your research? Choose BMC and benefit from:

- fast, convenient online submission

- thorough peer review by experienced researchers in your field

- rapid publication on acceptance

- support for research data, including large and complex data types

- gold Open Access which fosters wider collaboration and increased citations

- maximum visibility for your research: over $100 \mathrm{M}$ website views per year

At $\mathrm{BMC}$, research is always in progress.

Learn more biomedcentral.com/submissions 